\title{
An investigation of physical and mental health consequences among Chinese parents who lost their only child
}

\author{
Qianlan Yin ${ }^{1 \dagger}$, Zhilei Shang ${ }^{1 \dagger}, \mathrm{Na}_{\text {Zhou }}{ }^{\dagger}$, Lili Wu', Guangyu Liu' ${ }^{1}$ Xiaoqian Yu², Huaihui Zhang ${ }^{3}$, Haidong Xue ${ }^{4}$
} and Weizhi Liu*

\begin{abstract}
Background: The term "loss-of-only-child family" means that the only child in a family passed away or is disabled due to an accident or other events. The parents who cannot conceive or do not adopt another child, are known as Shidu parents in China. This study compares the physical and mental health of Shidu parents with those parents who have not experienced such loss.

Methods: The target group is comprised of parents being Shidu for more than 1 year $(N=95)$ and the control group is comprised of parents with a living child ( $N=97)$ from the same area as the Shidu parents. Socio-demographic information and physical health outcomes were collected by the adapted questionnaires. PCL-C (PTSD Checklist-Civilian Version), CES-D (Center for Epidemiological Studies Depression Scale) and GHQ-12 (General Health Questionnaire) were applied to evaluate the parents' physical and mental status.

Results: Shidu parents have a higher risk of developing PTSD and depression, and suffer more severe psychiatric disorders compared to parents with a living child. The rate of PTSD in the Shidu group was up to $32.6 \%$ and the scores of PCL-C are much higher than the control group. The physical status of Shidu parents were much worse than that of the control group, characterized by higher morbidity of chronic diseases and more hospital visits.

Conclusions: Shidu parents have more severe mental health problems and a higher rate of chronic diseases than parents who have a living child. Loss of the only child is the most traumatic event for the parents, which is a serious and unique problem in Chinese society that deserves attention. More studies and support are desired to improve the physical and mental health of Shidu parents.
\end{abstract}

Keywords: Loss-of-only-child family, Shidu parents, Mental and physical health, PTSD

\section{Background}

"Loss-of-only-child family" means that the only child in a family passed away or is disabled due to an accident, and the mother has passed her reproductive age [1]. These parents are referred to as Shidu parents in Chinese society. The number of one-child families in China has exploded in the past 30 years as a result of the only-child policy $[2,3]$. To illustrate, among people age 25 to 29 (born in 1980 to 1990), 15\% of them are

\footnotetext{
* Correspondence: liuweizhi@smmu.edu.cn

${ }^{\dagger}$ Equal contributors

${ }^{1}$ Faculty of Psychology and Mental Health, Second Military Medical

University, 800 Xiangyin Road, Shanghai 200433, China

Full list of author information is available at the end of the article
}

from only-child families. However, the percentage nearly quadrupled among those born after 2000 [4]. According to the population census statistics in 2011, about 76,000 Shidu families occur each year [5], and the number of Shidu families in China will reach one million in a decade based on the latest demographic statistics. Thus, the challenges this population is facing need to be addressed in order for the government to better assist them.

One obvious challenging this population is facing is the grief caused by losing the only child. Several studies have suggested that sudden death (e.g. from an earthquake or accident) of a loved one is an important risk factor for PTSD [6-10] and depression [10, 11]. Although these studies on parental bereavement 
have provided significant insights and theoretical perspectives to understand Shidu parents, the majority of the studies are about the mental consequences of losing relatives, spouses, siblings and others, very few of them are specifically about losing an only child, which may raise different concerns from losing other family members. This is especially true for Chinese parents. Chinese culture is family-oriented. Children and parents form a very close relationship, and children live with their parents till college or marriage. Parents take care of their young children and children are their aging parents' main care-giving providers. This is not only a phenomenon stem from cultural awareness but also an obligation enforced by law. For parents, losing the only child often means losing their main source of care-giving, termination of the family line, a great threat to the individual's well-being [12], and consequences of declining mental health or social withdrawal, which may progress to a point of social isolation because communicating about their child's death is often difficult and can be hurtful and stigmatizing. According to the studies conducted with the bereaved people, the death of a child results in a significantly high intensity of unresolved grief, which can worsen mental and physical health [13-16]. To date, only one study [17] has been conducted in mainland China to investigate Shidu, and it indicates that with reduced family members as a result of the population control, the unexpected death of a beloved one can be more devastating and traumatic for other family members than the days before the population control. Therefore, besides financial support, social support in the form of grief counseling is also needed to prevent the declining of mental health $[18,19]$. At the moment, not enough social workers in China can provide such counseling service, and therefore institutes need to be established to train these social workers.

In summary, Shidu is a unique social issue in Chinese society after the decades-long one-child policy [20]. Therefore, Chinese government has been aware of the importance of providing support for Shidu parents. Considering the growing population in Shidu, and the lack of systematic investigation of the health consequences arising in this population, our study aimed to examine different facets of health status in Shidu parents, thus to add the corresponding assistance from the government.

In the present study, we administered questionnaires to collect data on the physical and psychological health status of Shidu parents and parents with a living child in the Yangpu district of Shanghai. We hypothesized that Shidu parents would have more severe mental problems and a higher rate of chronic diseases than parents with a living child.

\section{Method}

\section{Participants and procedure}

We obtained information about the Shidu parents from the Register of Population Statistics provided by the Health Family Planning Commission of Yangpu District, Shanghai. One hundred and ten out of 800 Shidu families were randomly selected from 11 communities of Yangpu district in Shanghai (we only selected one parent from each "loss-of-only-child family" as our participant). We organized a team including a psychologist, a psychiatrist and several psychology graduate students to investigate the Shidu parents under help from local social workers knowing the families. A household survey was also administered to the Shidu parents, which took approximately 30-40 min to complete. Some participants became emotional during the investigation, we had to pause the investigation to comfort them, thus the entire investigation process can take $1-2 \mathrm{~h}$. The parents were instructed to read the recruitment letter detailing the purpose, method, and procedure of the study, they were assured of anonymity and confidentiality in the reporting of the results, and the right to withdraw from the study anytime. Researcher's contact information was given out to the participants, research ethics were carefully considered prior to the study. This study was approved by the ethics committees of the Second Military Medical University.

The criteria for the target group are listed below:

1. Shidu parents above 49 passed the reproductive age or do not want another baby.

China's general birth control policy was transformed into the one-child policy nationwide in 1980's. As the legal age of marriage is 22 for men and 20 for women, those who complied with the policy would be at the age of more than 49 . Therefore in this study, both Shidu parents and the parents with a living child were above 49 , the latest childbearing age. Besides, Shidu parents have not adopted a child by the time they participated in this study.

2. They could read and understand the questionnaires and completed all the questions (parents with serious mental diseases such as schizophrenia were excluded).

3. Shidu parents lost their only child 1 year ago.

We performed stratified random sampling according to the ratio of $1: 1$ in the same area from April to November in 2015. The control group has the same sample size as the target group, and both groups are equally distributed in gender, age and family incomes.

\section{Measures}

Demographic information: gender, age, nationality, place of residence, religious belief, educational background, 
marital status and subjective assessment of family economic status (according to the average monthly household income in Shanghai in 2015, "below 3000 yuan" is considered as bad; "over 3000 yuan" as good).

PTSD Checklist-Civilian Version (PCL-C) to screen for bereavement-related PTSD, developed by Weathers et al. [21]. We used a self-report instrument that corresponds to the PTSD criteria according to the Diagnostic and Statistical Manual of Mental Disorders, Fourth Edition [22]. Participants responded to 17 items on a 5-point Likert-Type scale $(1=$ not at all, and $5=$ extremely) in three areas: intrusion, avoidance and numbing, and hyperarousal. The Chinese version of the PCL-C has shown excellent internal consistency and convergent validity with other measures of PTSD severity in previous studies [23].

Depressive symptoms were measured with the 20-item Center for Epidemiological Studies Depression Scale (CES-D) [24]. The CES-D asks subjects how often they experienced a number of situations or feelings in the past week. Possible responses range from 0 ("rarely or none of the time [less than 1 day]") to 3 ("most or all of the time [5-7 days]"). The composite scores of the CES$\mathrm{D}$ items range from 0 to 60 , with higher scores indicating more frequent symptoms. The internal consistency is 0.84 . The measurement has the same validity in China [25] as in Western countries [26].

The General Health Questionnaire (GHQ-12) was used to evaluate the severity of general psychiatric morbidity. As a shortened version of the GHQ-60, it is well adjusted for long-term studies that require an indicator of minor psychiatric morbidity and has proved to be valid in both the clinical and general populations [27]. The Chinese version of the GHQ-12 has sound reliability and validity of the diagnostic performance [28]. The 12 items scored on the basis of $0-0-1-1$ (the first 2 answer scores were 0 and the 2 following scores were 1 ). The total scores range from 0 to 12 , with higher scores indicating worse health conditions. The internal consistency of the GHQ-12 in the present study was 0.85 .

Questionnaires for physical health outcomes included two items. One is designed for collecting information on whether the participants had common chronic diseases including hypertension, coronary heart disease, diabetes mellitus, cerebrovascular diseases (such as cerebral stroke, congestion and hemorrhage), diseases of digestive system (such as chronic gastritis, enteritis, hepatitis, cholecystitis, gall-stone, and polypus) and respiratory system (such as chronic bronchitis, pneumonectasis, asthma and tuberculosis), rheumatism (such as rheumatic condition and pain in joint), osteoarthropathy (such as hypertrophic, tuberculous and retromorphosis), tumor, mental illnesses and so on. The other item measures the number of outpatient physician visits for physical health or other reasons. It was ranked in 4 levels $(1=0-2$ times, $2=3-5$ times, $3=6-9$ times, $4=$ equal to or greater than 10 times).

\section{Data analysis}

We collected 95 valid questionnaires out of 110 Shidu parents according to the criteria (with ten declining our investigation and five failing to meet the criteria). To maintain the same sample size as the target group, 100 families were selected as the control group from the 11 communities, and 97 questionnaires were collected. Analyses were conducted using IBM Statistical Package for Social Sciences version 20. Missing values (less than $5 \%$ ) were replaced by the sample mean. Chi-square and $t$ tests were carried out for further analysis.

\section{Results}

Demographic information of the two groups is presented in Table 1. Chi-square tests revealed no significant difference between Shidu and the control group in terms of gender $\left(\chi^{2}=0.04, p=0.83\right)$, marital status $\left(\chi^{2}=0.41\right.$,

Table 1 Demographic Statistics for "Shidu" Group and Normal Group

\begin{tabular}{|c|c|c|c|c|c|c|}
\hline & \multicolumn{2}{|c|}{$\begin{array}{l}\text { Control Group } \\
N=97\end{array}$} & \multicolumn{2}{|c|}{$\begin{array}{l}\text { "Shidu" Group } \\
N=95\end{array}$} & \multirow[t]{2}{*}{$x^{2}$} & \multirow[t]{2}{*}{$p$-value } \\
\hline & $\bar{n}$ & $\%$ & $\bar{n}$ & $\%$ & & \\
\hline \multicolumn{7}{|l|}{ Gender } \\
\hline Female & 65 & 67.01 & 65 & 68.42 & 0.04 & 0.83 \\
\hline Male & 32 & 32.99 & 30 & 31.58 & & \\
\hline \multicolumn{7}{|l|}{ Age } \\
\hline $50-64$ & 47 & 48.45 & 66 & 69.47 & 8.76 & $<.001 * * *$ \\
\hline $65-80$ & 50 & 51.55 & 29 & 30.53 & & \\
\hline \multicolumn{7}{|l|}{ Marital status } \\
\hline Married & 85 & 87.63 & 84 & 88.42 & 0.41 & 0.82 \\
\hline Divorced & 2 & 2.06 & 3 & 3.16 & & \\
\hline Widowed & 10 & 10.31 & 8 & 8.42 & & \\
\hline \multicolumn{7}{|l|}{ Educational Level } \\
\hline $\begin{array}{l}\text { Lower than } \\
\text { high school }\end{array}$ & 42 & 43.30 & 50 & 52.63 & 3.26 & 0.20 \\
\hline High school & 45 & 46.39 & 32 & 33.68 & & \\
\hline $\begin{array}{l}\text { Over than } \\
\text { high school }\end{array}$ & 10 & 10.31 & 13 & 13.68 & & \\
\hline \multicolumn{7}{|l|}{ Religion Belief } \\
\hline None & 80 & 82.47 & 76 & 80.00 & 1.10 & 0.58 \\
\hline Buddhism & 11 & 11.34 & 15 & 15.79 & & \\
\hline Other & 6 & 6.19 & 4 & 4.21 & & \\
\hline \multicolumn{7}{|l|}{ Family income } \\
\hline Below 3000 & 52 & 53.61 & 35 & 36.84 & 5.44 & $0.02^{*}$ \\
\hline 3000 and over & 45 & 46.39 & 60 & 63.16 & & \\
\hline
\end{tabular}

Note. ${ }^{*} p$-value $<.05 ;{ }^{* * *} p$-value $<.001$ 
$p=0.82)$, educational level $\left(\chi^{2}=3.26, p=0.20\right)$, and religious belief $\left(\chi^{2}=1.10, p=0.58\right)$, but there is a significant difference when it comes to age $\left(\chi^{2}=8.76, p<0.01\right)$ and family income $\left(\chi^{2}=5.44, p=0.02\right)$.

Table 2 shows the group differences in PTSD, depressive symptoms, and general health condition. Results from the t-tests indicated that the Shidu group scored significantly higher on all the scales than the control group, implying that the Shidu parents were more vulnerable to develop PTSD, depressive and mental illness symptoms than the parents with a living child.

On the PCL-C, we set a cut-off of 50 to suggest a PTSD diagnosis [29]. The results showed that the highest score of the Shidu was 81, the lowest was 17, and over 50 participants totaled 31 . The rate of PTSD in the Shidu group was up to $32.6 \%$ with 26 females and five males, and the women $\left(\mathrm{PTSD}_{\text {female }}=40.0 \%\right)$ had a higher positive rate of PTSD than men $\left(\mathrm{PTSD}_{\text {male }}=16.7 \%\right)$. We conclude from these data that the Shidu parents had higher morbidity than the control group, and women were more likely to develop PTSD than men.

We collected the morbidity of chronic diseases (which included hypertension, coronary heart disease, diabetes mellitus, cerebrovascular diseases, diseases of the digestive system, diseases of the respiratory system, arthritis, osteoarthrosis, tumors, mental diseases and so on), and the number of visits to a hospital in recent years mainly to assess the level of physical health. We observed a significantly higher overall morbidity of coronary heart disease $\left(\chi^{2}=23.355, p<.01\right)$, tumors $\left(\chi^{2}=4.828, p=.028\right)$, mental diseases $\left(\chi^{2}=4.828, p=.028\right)$ and other unclassified diseases $\left(\chi^{2}=6.887, p=0.009\right)$ in the Shidu parents than the parents with a living child from Table 3. According to the total number of visits to the hospital in recent years (see Table 4 for the comparison of the number of visits to a hospital in the two groups), the Shidu group had more visits to the hospital than the control group $\left(\chi^{2}=17.362, p=0.001\right)$. 54 (56.8\% of the total) Shidu parents visited the hospital more than 10 times, while the corresponding number in the control group is 28 (28.9\% of the total). In conclusion, Shidu parents have worse physical health conditions compared to the parents with a living child.

Table 2 "Shidu" parents Compared With The Normal in the scales

\begin{tabular}{|c|c|c|c|c|c|c|}
\hline & \multicolumn{2}{|c|}{$\begin{array}{l}\text { Control Group } \\
N=97\end{array}$} & \multicolumn{2}{|c|}{$\begin{array}{l}\text { "Shidu" Group } \\
N=95\end{array}$} & \multirow[t]{2}{*}{$\mathrm{t}$} & \multirow[t]{2}{*}{$p$-value } \\
\hline & Mean & SD & Mean & SD & & \\
\hline PCL-C & 23.90 & 7.29 & 45.28 & 15.85 & -11.970 & $<.001^{* * *}$ \\
\hline CES-D & 3.47 & 5.17 & 16.33 & 14.64 & -8.076 & $<.001^{* * *}$ \\
\hline GHQ-12 & 0.58 & 0.91 & 3.74 & 3.90 & -7.702 & $<.001^{* * *}$ \\
\hline
\end{tabular}

Note. PCL-C PTSD Checklist-Civilian Version, CES-D Center for Epidemiological Studies Depression Scale, GHQ-12 The General Health Questionnaire ${ }^{* * *} p$-value $<.001$
Table 3 The comparison of mortality in the two groups

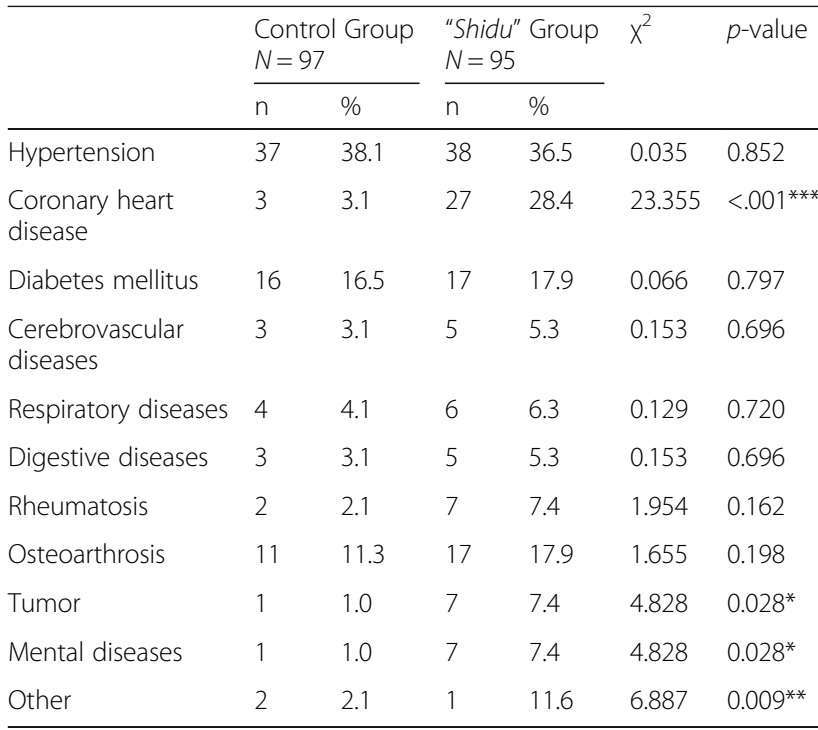

Note. ${ }^{*} p$-value $<.05 ;{ }^{* *} p$-value $<.01 ; * * * p$-value $<.001$

\section{Discussion}

The purpose of the current study was to test the assumption that Shidu parents have impaired physical and mental health due to losing an only child by comparing a group of Shidu parents to their counterparts with a living child. The comparison was based on a series of standardized assessments of their physical health and mental health problems such as PTSD and depression. The results of this study have confirmed the hypothesis that PTSD and depressive symptoms are more common in Shidu parents than the control group.

Children are the major source of joy, hope, meaning, and purpose in life for all parents, and it is the most devastating grief for parents to lose a loved child [30]. The loss of an only child is particularly traumatizing and heartbreaking for Chinese parents as a result of the "one-child" policy and the cultural role that children play in a Chinese family. Although China is becoming more westernized, Confucianism still represent the core values of Chinese society. One of the values is making the passing on the family name an obligation, failing to do so triggers a great deal of stress [31]. Children are the

Table 4 The comparison of the visit time to hospital in the two

\begin{tabular}{|c|c|c|c|c|c|c|}
\hline \multirow[t]{2}{*}{ Times } & \multicolumn{2}{|c|}{$\begin{array}{l}\text { Control Group } \\
n=97\end{array}$} & \multicolumn{2}{|c|}{$\begin{array}{l}\text { "Shidu" Group } \\
n=95\end{array}$} & \multirow[t]{2}{*}{$x^{2}$} & \multirow[t]{2}{*}{$\overline{p \text { value }}$} \\
\hline & $\mathrm{N}$ & $\%$ & $\mathrm{~N}$ & $\%$ & & \\
\hline $0-2$ & 33 & 34.0 & 18 & 18.9 & 17.362 & 0.001 \\
\hline $3-5$ & 28 & 28.9 & 14 & 14.7 & & \\
\hline $6-9$ & 8 & 8.2 & 9 & 9.5 & & \\
\hline$>=10$ & 28 & 28.9 & 54 & 56.8 & & \\
\hline Total & 97 & 100.0 & 95 & 100.0 & & \\
\hline
\end{tabular}


main caregivers of their aging parents [32, 33], and play an indispensable role in maintaining the family line. Shidu parents can feel extremely desperate and overwhelmed about the termination of their family line (especially those who could no longer conceive), and they are highly vulnerable to PTSD and depressive symptoms. As a result, systematic and culturally sensitive psychological assistance and mental health services should be provided to this particular group of bereaved parents.

Many studies have recognized the psychological and physical consequences of losing a loved child [14], but very few studies have addressed in detail the physical effects. Our results showed a higher morbidity in coronary heart disease, tumors, mental diseases and other unclassified diseases in the Shidu group compared to the control. These diseases were closely related to the longterm psychological suffering of losing the only child. More importantly, the parents in our study became Shidu only 1 year ago, so for parents being Shidu longer, the physical and mental health consequences could be much more severe than our findings. In summary, it is urgent to offer support to prevent the diseases from worsening in Shidu parents. Our findings were consistent with a nationwide follow-up study in Denmark [34] and several studies in China [20] in revealing the difference between the Shidu group and control group in terms of health. However, from a clinical view of mental disease, 32.6\% of the Shidu group in our study have PTSD, much higher than the ratio from relevant studies $[35,36]$. Furthermore, our finding that women are more likely to develop PTSD and depression than men echoed western studies, which provide some explanation like the role expectations of women compared to men [35]. Given the role expectation in China, mothers are playing a bigger role in raising up their only child, and spend more time with the child than fathers, so mothers and children have a very closed relationship, therefore losing the only child raises more challenges for mothers than for fathers.

Several limitations in the design of this study should be taken into account when the results were evaluated. First, the actual physical and mental condition can be more severe than the results reported here, as some Shidu parents rejected the investigation since it was emotionally challenging for them to talk about the bereavement. Second, the sample were recruited from one area, which might have limited the ability to generalize to people from other areas with a different socialeconomic status. Although we have already included a larger scale than the previous studies, the sample should be extended considering the large population of Shidu parents in China. Third, there were differences in demographic information in the two groups. Poor health condition and syptoms of PTSD were more likely to be observed among the Shidu group even though the Shidu group were wealthier and younger than their counterparts. However, the differences didn't impact the results in a significant way, instead those indirectly supported our attribution of sever experience of losing the only child mainly damaging their physical and mental health. In fact, although the data collection process was not as smooth as expected due to the sensitive and emotional topic of Shidu, we were still able to collect ample samples with the help of the committee workers.

To summarize, this study has provided a picture of the current health condition of Shidu parents, and we hope to stimulate the development of corresponding regulations and services to improve their life quality. For instance, the findings have demonstrated the need to enhance health care to Shidu parents, and to intervene with those who did not go to clinical services regularly or were unwilling to get clinical services. Further investigation is needed to explore some other predictors responsible for the prevalence of PTSD and depression in Shidu parents, such as the personality of the parents, the characteristics of the lost children, and the social environment [37]. More studies can be beneficial to address the factors causing the differences between the Shidu parents and the parents with a living child.

\section{Conclusion}

Shidu parents have more severe mental health problems and a higher rate of chronic diseases than their counterparts who have a living child. Losing the only child is the most traumatic event for senior parents who cannot conceive, which is a serious and unique problem in Chinese society due to the one-child policy. More support is needed to help Shidu parents to improve their health status, and more studies are desired to address the problems and challenges this population is facing, in order to better their life quality.

\section{Abbreviations}

CES-D: Center for Epidemiological Studies Depression Scale; GHQ-12: General Health Questionnaire; PCL-C: PTSD Checklist-Civilian Version; PTSD: Post-trauma syndrome disease

\section{Acknowledgments \\ The authors would like to acknowledge the volunteers who participated in the study and appreciate the endeavor of the social workers from the Yangpu District Youyun Social Work Office. We also pay tribute to the cooperation of the Mental Health Center of Shanghai Yangpu District.}

\section{Funding}

This research was supported in part by a grant from Shanghai Pujiang Program (13PJC003) and Innovation Program of Shanghai Municipal Education Commission(14ZS084).

Availability of data and materials

The datasets analyzed and materials used in this study are available from the corresponding author $(\mathrm{WL})$ on reasonable request. 


\section{Authors' contributions}

QY, ZS, NZ contributed to the writing of this article and part of statistical analysis. WL leaded the whole study, including putting forward this study, getting funding source and carrying out the study, and was the corresponding author. XY contributed to revise this article and part of statistical analysis. GL, LW $\mathrm{HX}$ contributed to perform the investigation and collection of all data. $\mathrm{HZ}$ was responsible for the diagnosis of PTSD, and helped to collect the data. We are all accountable for all aspects of the work in ensuring that questions related to the accuracy or integrity of any part of the work are appropriately investigated and resolved. We all agree to submit our research result in the article to BMC Psychiatry Research. All authors read and approved the final manuscript.

\section{Ethics approval and consent to participate}

This study was approved by the ethics committees of the Second Military Medical University. A complete survey description was first presented to the participants. Informed written consent, together with oral approvals, was obtained before the testing session according to the Declaration of Helsinki.

\section{Consent for publication}

Not applicable.

\section{Competing interests}

The authors declare that they have no competing interests.

\section{Publisher's Note}

Springer Nature remains neutral with regard to jurisdictional claims in published maps and institutional affiliations.

\section{Author details}

${ }^{1}$ Faculty of Psychology and Mental Health, Second Military Medical University, 800 Xiangyin Road, Shanghai 200433, China. ${ }^{2}$ Department of psychology, University of South Florida, Tampa, USA. ${ }^{3}$ Mental Health Center of Yangpu District, Shanghai, China. ${ }^{4}$ Health Family Planning Commission of Yangpu District, Shanghai, China.

Received: 23 January 2017 Accepted: 28 January 2018

Published online: 12 February 2018

\section{References}

1. Chen E. The number of the only child died families in China. Popul Dev. 2013;19:100-3.

2. Mu GZ. Aiding and caring the emergency of the family sacrificing for the fertility policy. Popul Dev. 2008;14:27-30.

3. Xiao L, Sun M, Wang QY, Tang SY. The dilemma and copy strategy of the only child died families in China. Chin J Gerontol. 2016;36(3):742-4.

4. Huang YN. Millions of loss-single-child families in China. Modern Reading. 2011;155:52-4.

5. The popular research project of Peking University. The study about the caring system of loss-of-single-child families sampled in Liaoning province. Chin J Yanan Cadre Inst. 2011:4:50-60.

6. Basoglu M, Salcioglu E, Livanou M. Traumatic stress responses in earthquake survivors in Turkey. J Trauma Stress. 2002;15:269-76.

7. Basoglu M, Kilic C, Salcioglu E, Livanou M. Prevalence of post-traumatic stress disorder and comorbid depression in earthquake survivors in Turkey: an epidemiological study. J Trauma Stress. 2004;17:133-41.

8. Jia Z, Tian WH, Liu WZ, Cao Y, Yan J, Shun ZS. Are the elderly more vulnerable to psychological impact of natural disaster? A population-based survey of adult survivors of the 2008 Sichuan earthquake. BMC Public Health. 2010:30(10):172. http://dx.doi.org/10.1186/1471-2458-10-172

9. Kun P, Han S, Chen X, Yao L. Prevalence and risk factors for post-traumatic stress disorder: a cross-sectional study among survivors of the Wenchuan 2008 earthquake in China. Depress Anxiety. 2009;26(12):1134-40.

10. Van Griensven F, Chakkraband ML, Thienkrua W, Pengjuntr W, Lopes Cardozo B, Tantipiwatanaskul P, et al. Mental health problems among adults in tsunamiaffected areas in southern Thailand. J Am Med Assoc. 2006;296:537-48.

11. Livanou M, Basoglu M, Salcioglu E, Kalendar D. Traumatic stress responses in treatment-seeking earthquake survivors in Turkey. J Nerv Ment Dis. 2002; 190:816-23.

12. Zheng Y, Lawson TR. Identity reconstruction as Shiduers: narratives from Chinese older adults who lost their only child. Int J Soc Welf. 2014;24(4) https://doi.org/10.1111/ijsw.12139.
13. Fletcher PN. Experiences in family bereavement. Fam Community Health. 2002;25:57-70.

14. Rogers CH, Floyd FJ, Seltzer MM, Greenberg J, Hong J. Long-term effects of the death of a child on parents' adjustment in midlife. J Fam Psychol. 2008; 22:203-11.

15. Kristensen P, Weisaeth L, Heir T. Bereavement and mental health after sudden and violent losses: a review. Psychiatry. 2012;75:76-97.

16. Rostila M, Saarela J, Kawachi I. Mortality in parents following the death of a child: a nationwide follow-up study from Sweden. J Epidemiol Community Health. 2012;66:927-33.

17. Yuan Y, Mao W-J, Yang D-H, Ran M-S, Kong D, Zhang T, et al. Comparison of the PTSD symptoms, depression and anxiety between bereaved and non-bereaved survivors after Wenchuan earthquake. Chin J Behav Med Brain Sci. 2009;18:1109-11.

18. Hang RH. A study about the mental reaction and coping strategy and social support among the loss-of-single-child families. J Youjiang Med Univ Nationalities. 2013:35:846-8.

19. Mu GZ. The prospective risk of Chinese popular changes. J Zheijang Univ. 2006;36:24-32.

20. Zheng Y, Lawson TR, Barbara AH. "Our only child has died": a study of bereaved older Chinese parents. J Death Dying. 2015;0(0):1-16. https://doi. org/10.1177/0030222815612285.

21. Weathers FW, Litz BT, Herman DS, Huska JA, Keane TM. The PTSD checklist (PCL): reliability, validity, and diagnostic utility. In: Paper Presented at the Annual Meeting of the International Society for Traumatic Stress Studies. San Antonio, TX; 1993.

22. American Psychiatric Association. Diagnostic and statistical manual of mental disorders: DSM-IV. Washington, DC: American Psychiatric Publishing; 1994.

23. Yang $X$, Yang $\mathrm{H}$, Liu Q. The research on the reliability and validity of $\mathrm{PCL}-\mathrm{C}$ and influence factors. Chin J Health Psychol. 2007;15(1):6-9.

24. Radloff LS. The CES-D scale: a self-report depression scale for research in the general population. Appl Psychol Meas. 1977;1:385-401.

25. Cheng ST, Chan A. The center for epidemiologic studies depression scale in older Chinese: thresholds for long and short forms. Int I Geriatr Psychiatry. 2005:20:465-70.

26. Turvey CL, Wallace RB, Herzog R. A revised CES-D measure of depressive symptoms and a DSM-based measure of major depressive episodes in the elderly. Int Psychogeriatr. 1999;11:139-48.

27. Pevalin D. J. . Investigating long-term retest effects in the GHQ-12 (no. 2000-20). ISER (Institute for Social and Economic Research) working paper series, university of Essex; 2000 https://www.econstor.eu/dspace/bitstream/ 10419/92016/1/2000-20.pdf.

28. Pan PC, Goldberg DP. A comparison of the validity of GHQ-12 and CHQ-12 in Chinese primary care patients in Manchester. Psychol Med. 1990;20:931-40.

29. Brewin CR. Systematic review of screening instruments for adults at risk of PTSD. J Trauma Stress. 2005;18:53-62.

30. Bolton JM, Au W, Leslie WD, Martens PJ, Enns MW, Roos LL, et al. Parents bereaved by offspring suicide: a population-based longitudinal case control study. JAMA Psychiatry. 2013;70:158-67.

31. Chan CL, Chow AY, Ho SM, Tsui YK, Tin AF, Koo BW, Koo EW. The experience of Chinese bereaved persons: a preliminary study of meaning making and continuing bonds. Death Studies. 2005;29(10):923-47.

32. Lee AEY. Family social support patterns of the Chinese elderly in Beijing, shanghai, Guangzhou and Los Angeles: the role of filial piety. Diss Abstr Int. 1998:58:37-23.

33. Upton Mclaughlin, S.. The significance of family in China. 2013 The China Culture Corner. https://chinaculturecorner.com/2013/06/21/the-chinese-family

34. Jiong L, Dorthe HP, Preben BM, Jørn O. Mortality in parents after death of a child in Denmark:a nationwide follow-up study. Lancet. 2003:361:363-7.

35. Murphy SA, Clark Johnson L, Chung IJ, Beaton RD. The prevalence of PTSD following the violent death of a child and predictors of change 5 years later. J Trauma Stress. 2003;16:17-25.

36. He L, Tang S, Yu W, et al. The prevalence, co-morbidity and risks of prolonged grief disorder among bereaved Chinese adults. Psychiatry Res. 2014;219(2):347-52.

37. Lee C, Glei DA, Weinstein M, Goldman N. Death of a child and parental well-being in old age: evidence from Taiwan. Soc Sci Med. 2014;101:166-73. 